\title{
How Should the FDA Review Diagnostic Radiopharmaceuticals?
}

\author{
Carol S. Marcus \\ Departments of Molecular and Medical Pharmacology, Radiation Oncology, and Radiological Sciences, David Geffen School of \\ Medicine, University of California, Los Angeles, California
}

\section{See an invited perspective on this article on page 865 .}

The purpose of this article is to reconsider the manner in which the U.S. Food and Drug Administration (FDA) reviews diagnostic radiopharmaceuticals. Mass characteristics of several common nonradioactive drugs and several diagnostic radiopharmaceuticals are considered. A history of the regulation of radiopharmaceuticals is presented. The Society of Nuclear Medicine and Molecular Imaging and the American College of Nuclear Medicine should choose the membership of a radiopharmaceutical advisory committee, and the FDA should contract with them to do so. Members of the radiopharmaceutical advisory committee should decide on the data to be presented by the manufacturer or the compounder and review those data, and the FDA should honor their decision. In this way, requirements would be radiopharmaceutical-specific, and much information of questionable usefulness would be foregone.

Key Words: diagnostic radiopharmaceutical regulation; FDA regulation; diagnostic radiopharmaceutical advisory committee

J Nucl Med 2018; 59:868-870

DOI: 10.2967/jnumed.117.200337

H ow many aspirin, acetaminophen, or ibuprofen tablets will you take over your lifetime? How many antacid tablets? How about vitamin $\mathrm{C}$ tablets or atenolol? Probably the answer is thousands. How many doses of diagnostic radiopharmaceuticals will you take in a lifetime? A few, up to 10 or so, probably. The masses of unknown compounds in your aspirin, acetaminophen, ibuprofen, antacid, vitamin C, and atenolol (1) (Table 1) are greater than the masses of many radiopharmaceuticals, often by 3-6 orders of magnitude (according to their U.S. Food and Drug Administration [FDA]-approved package inserts, except for ${ }^{15} \mathrm{O}-\mathrm{H}_{2} \mathrm{O}$, which is not FDA-approved) (Table 2). Some radiopharmaceuticals have masses on a par with the permitted unknown compounds of these nonradioactive drugs, often because of excess ligand in kits. Although mass in and of itself is not the most important safety aspect of a drug (toxicity is), we are not dealing with deadly molecules such as tetrodotoxin here. Most diagnostic radiopharmaceuticals belong to classes of drugs known not to be highly toxic in tiny masses.

Received Aug. 2, 2017; revision accepted Oct. 6, 2017.

For correspondence or reprints contact: Carol S. Marcus, UCLA, 1877

Comstock Ave., Los Angeles, CA 90025.

E-mail: csmarcus@ucla.edu

Guest Editor: David Mankoff, University of Pennsylvania.

Published online Oct. 12, 2017.

COPYRIGHT (C 2018 by the Society of Nuclear Medicine and Molecular Imaging.
The FDA does not know exactly what these contaminant compounds are in the nonradioactive drugs, but as long as the nonradioactive drug passes its toxicity testing, it is assumed that these contaminants are not important. In many cases there is only a heavy metal limit, generally in microgram quantities, but the FDA treats radiopharmaceuticals as ordinary drugs, requiring all the pharmacologic and toxicologic and animal testing on them anyway. This complicates the FDA's radiopharmaceutical approval process and increases its costs. A few decades ago, a "physician-sponsored investigational-new-drug application" was trivial, and human trials of new diagnostic radiopharmaceuticals could proceed without extensive pharmacologic, toxicologic, and animal testing. That is no longer the case. As far as the radiation from radiopharmaceuticals is concerned, we know what radiation at different levels causes (2), and we do not need to keep showing it repeatedly. When the FDA approves devices for radiation oncology, it is the physician who decides how much radiation to use from that device, and clinical trials of this factor are not required for device approval. FDA review of diagnostic radiopharmaceuticals merits a significant change in requirements, with each new radiopharmaceutical evaluated for what is truly necessary and sufficient to demonstrate safety and efficacy, instead of extensive and expensive one-size-fits-all requirements.

\section{HISTORY}

For us to see this problem in perspective, some history is in order. Modern nuclear medicine began in 1936, when John Lawrence in California treated polycythemia vera patients with ${ }^{32} \mathrm{P}$-sodium phosphate made on the Berkeley cyclotron. A very short time later, physicians in Boston began using various radionuclides of iodine to study thyroid function, the radionuclides coming from the Massachusetts Institute of Technology cyclotron. The FDA did not regulate these radiopharmaceuticals, and as there was no radiation regulator, physicians did what they thought reasonable with no regulatory oversight except for state medical boards.

During the second world war, the physicists and radiochemists from Berkeley were swept into the Manhattan Project, and there was no one left at Berkeley to make the ${ }^{32} \mathrm{P}$-sodium phosphate to ship all over the country for polycythemia vera therapy. Scientists at the topsecret Oak Ridge nuclear reactor, built to produce plutonium for atomic bombs, obligingly made ${ }^{32} \mathrm{P}$ on the reactor and shipped the ${ }^{32} \mathrm{P}$-sodium phosphate to Berkeley, and from there it was delivered all over the country. The public did not realize what had been going on until after the war. In 1946, the Oak Ridge reactor scientists made ${ }^{131}$ I-sodium iodide available for hyperthyroid and thyroid cancer diagnosis and therapy. When the Atomic Energy Act was passed in 1954 and the Atomic Energy Commission (AEC) was formed, the AEC assumed regulation of radiopharmaceuticals (the FDA exempted radiopharmaceuticals from its regulatory purview). To 


\begin{tabular}{|c|c|}
\hline Pharmaceutical & U.S. Pharmacopeia purity requirements \\
\hline Acetaminophen (325-mg tablet) & $\begin{array}{l}\text { Acetaminophen contains no less than } 98.0 \% \text { and no more than } 101.0 \% \mathrm{C}_{8} \mathrm{H}_{9} \mathrm{NO}_{2} \text {, } \\
\text { calculated on an anhydrous basis, of which no more than } 0.014 \% \text { can be as } \\
\text { chloride, } 0.02 \% \text { as sulfate, } 0.001 \% \text { as heavy metals, } 0.005 \% \text { as } p \text {-aminophenol, } \\
\text { and } 0.001 \% \text { as } p \text {-chloroacetanilide. Therefore, there can be up to } 6.5 \mathrm{mg} \text { of } \\
\text { unknowns in a } 325-\mathrm{mg} \text { tablet, of which } 3.25 \mu \mathrm{g} \text { may be heavy metals. }\end{array}$ \\
\hline Acetylsalicylic acid (aspirin, 325-mg tablet) & $\begin{array}{l}\text { Aspirin contains no less than } 99.5 \% \text { and no more than } 100.5 \% \mathrm{C}_{9} \mathrm{H}_{8} \mathrm{O}_{4} \text {, calculated } \\
\text { on a dried basis, of which no more than } 0.014 \% \text { can be as chloride, } 0.04 \% \text { as } \\
\text { sulfate, } 0.1 \% \text { as free salicylic acid, and } 10 \mu \mathrm{g} \text { as heavy metals per gram of aspirin. } \\
\text { Therefore, there can be up to } 1.6 \mathrm{mg} \text { of unknowns in a } 325-\mathrm{mg} \text { tablet, of which } \\
3.25 \mu \mathrm{g} \text { may be heavy metals. }\end{array}$ \\
\hline Atenolol (50-mg tablet) & $\begin{array}{l}\text { Atenolol contains no less than } 98.0 \% \text { and no more than } 102.0 \% \mathrm{C}_{14} \mathrm{H}_{22} \mathrm{~N}_{2} \mathrm{O}_{3} \text {, } \\
\text { calculated on a dried basis. No more than } 0.25 \% \text { of any individual } \\
\text { chromatographic impurity is found, and the sum of all chromatographic impurities } \\
\text { is no more than } 0.5 \% \text {. Therefore, there can be up to } 0.25 \mathrm{mg} \text { of unknown } \\
\text { chromatographic impurity per } 50-\mathrm{mg} \text { tablet, and there can be up to } 0.75 \mathrm{mg} \text { of } \\
\text { nonchromatographic impurity. }\end{array}$ \\
\hline Ascorbic acid (vitamin C, 500-mg tablet) & $\begin{array}{l}\text { Ascorbic acid contains no less than } 99.0 \% \text { and no more than } 100.5 \% \mathrm{C}_{6} \mathrm{H}_{8} \mathrm{O}_{6} \text {, with } \\
\text { no more than } 0.002 \% \text { heavy metals, or up to } 10 \mu \mathrm{g} \text { per } 500-\mathrm{mg} \text { tablet. }\end{array}$ \\
\hline $\begin{array}{l}\text { Rolaids (Chattem, Inc.) }\left(\mathrm{CaCO}_{3}, 675 \mathrm{mg} \text {, }\right. \\
\text { and } \mathrm{Mg}(\mathrm{OH})_{2}, 135 \mathrm{mg} \text {, in one tablet) }\end{array}$ & $\begin{array}{l}\mathrm{CaCO}_{3} \text { contains no less than } 98.0 \% \text { and no more than } 100.5 \% \mathrm{CaCO}_{3} . \text { Heavy metal } \\
\text { limit is } 0.002 \% \text {, or } 13.5 \mu \mathrm{g} / \mathrm{tablet} \text {; lead limit is } 3 \mathrm{ppm}(2 \mu \mathrm{g} / \mathrm{tablet}) ; \text { arsenic limit is } 3 \\
\mathrm{ppm}(2 \mu \mathrm{g} / \mathrm{tablet}) \text {; and mercury limit is } 0.5 \mu \mathrm{g} / \mathrm{g}(0.33 \mu \mathrm{g} / \mathrm{tablet}) . \mathrm{Mg}(\mathrm{OH})_{2} \text { contains } \\
\text { no less than } 95.0 \% \text { and no more than } 100.5 \% \mathrm{Mg}(\mathrm{OH})_{2} \text {. Heavy metal limit is } \\
20 \mu \mathrm{g} / \mathrm{g} \text {, or } 2.7 \mu \mathrm{g} / \mathrm{tablet} \text {, but lead is no more than } 0.202 \mu \mathrm{g} / \text { tablet. }\end{array}$ \\
\hline Ibuprofen (200-mg tablet) & $\begin{array}{l}\text { Ibuprofen contains no less than } 97.0 \% \text { and no more than } 103.0 \% \mathrm{C}_{13} \mathrm{H}_{18} \mathrm{O}_{2} \text {, } \\
\text { calculated on an anhydrous basis. Heavy metal limit is } 0.002 \% \text {, or } 4 \mu \mathrm{g} / \mathrm{tablet} \text {. }\end{array}$ \\
\hline
\end{tabular}

do this, the AEC formed an advisory committee on medical uses of isotopes, and approval was fast and inexpensive. Their principal advisor was Captain William H. Briner, who would ask a manufacturer to send him some of its radiopharmaceutical. Captain Briner would test it for purity and stability, inject a few rats, and image them. If it was stable and went where it was supposed to go, they would try it on a few patients. If it still localized as expected, he told the AEC to approve it. When the AEC was broken up into what became the Department of Energy and the Nuclear Regulatory Commission in 1974, Captain Briner remained a consultant to the Nuclear Regulatory Commission, which assumed regulatory authority over radiopharmaceuticals. Captain Briner estimated that with this regulatory system, it cost about $\$ 1,500$ to get a new radiopharmaceutical approved. No radiopharmaceutical recommended for approval by Captain Briner was ever taken off the market for reasons of safety or efficacy. As the radiopharmaceutical industry grew, the AEC felt that it should not be involved in the approval of radiopharmaceuticals because it did not know anything about these drugs. The AEC wanted the FDA to lift its exemption for radiopharmaceuticals and take over their regulation. And so, the FDA did this in 1975. And things have become much more complicated since then.

The first problem was that the expertise of the FDA directors and staff of the imaging division (which included x-ray contrast agents) in radiopharmaceuticals was limited. They simply looked at radiopharmaceuticals as ordinary drugs that were also radioactive, and they demanded the same testing for radiopharmaceuticals as was required for traditional, nonradioactive drugs. The cost of getting a new radiopharmaceutical through the FDA kept growing as more requirements were imposed on the manufacturers. Instead of $\$ 1,500$ to get a new drug approved, the costs went into the millions and tens of millions of dollars. And, of course, the costs of the diagnostic radiopharmaceuticals to patients once they were approved were also extremely high, as the manufacturers tried to recoup the development and regulatory costs. None of the new requirements of the FDA made the diagnostic radiopharmaceuticals any safer, because these tracers were generally safe to begin with. Thus, the FDA's regulatory approach did not contribute significantly to radiopharmaceutical safety.

Efficacy was simple under Captain Briner. If the agent went to the liver it was a liver scan agent. If it went to the lungs it was a lung scan agent. Nuclear medicine professionals and, more importantly, referring physicians, quickly understood whether a test was useful for their patients or not. Thus, given the safety of the approach, the users (physicians, patients) rather than the FDA decided whether a test was here to stay. The second problem arose with the FDA User Fee Program, initially opposed by the FDA, in which the FDA began charging manufacturers a user fee every year for every approved drug and every new approved indication. This led to an FDA situation in which radiopharmaceuticals were often approved only for limited indications, with the expectation that manufacturers would do more clinical trials for other indications. This resulted in more user fees paid to the FDA each year. Although physicians could use the radiopharmaceuticals for any indication they wanted, FDA-approved or not, the Center for Medicare and Medicaid Services often went into lock step with its sister agency the FDA and generally denied reimbursement for unlabeled indications. This put a financial penalty on physicians using radiopharmaceuticals for unlabeled indications and put pressure on manufacturers to perform more clinical trials. The FDA needs to return to appropriate pre-user-fee efficacy determinations. 
TABLE 2

Diagnostic Radiopharmaceuticals and Their Masses

\begin{tabular}{|c|c|}
\hline Diagnostic radiopharmaceutical & Mass $^{*}$ \\
\hline${ }^{15} \mathrm{O}-\mathrm{H}_{2} \mathrm{O}, 1,110 \mathrm{MBq}(30 \mathrm{mCi})$ & $5.55 \mathrm{pg}$ \\
\hline${ }^{18} \mathrm{~F}-\mathrm{NaF}, 370 \mathrm{MBq}(10 \mathrm{mCi})$ & $0.24 \mathrm{ng}$ \\
\hline${ }^{18} \mathrm{~F}-\mathrm{FDG}, 370 \mathrm{MBq}(10 \mathrm{mCi})$ & $1.06 \mathrm{ng}$ \\
\hline${ }^{13} \mathrm{~N}-\mathrm{NH}_{3}, 370 \mathrm{MBq}(10 \mathrm{mCi})$ & $400-800 \mathrm{ng}$ \\
\hline${ }^{18} \mathrm{~F}$-florbetapir, $370 \mathrm{MBq}(10 \mathrm{mCi})$ & About 300 ng \\
\hline 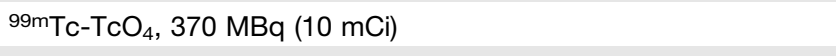 & $3.56 \mathrm{ng}+$ variable ${ }^{99} \mathrm{Tc}-\mathrm{TcO}_{4}$ \\
\hline 99mTc-MDP, 370-740 MBq (10-20 mCi), assumes 5 doses per kit & $2 \mathrm{mg}$ of medronate disodium \\
\hline 99mTc-MAG3, $185-370 \mathrm{MBq}(5-10 \mathrm{mCi})$, assumes 5 doses per kit & $0.2 \mathrm{mg}$ of betiatide \\
\hline 99mTc-sestamibi, $740 \mathrm{MBq}(20 \mathrm{mCi})$, assumes 5 doses per kit & $0.2 \mathrm{mg}$ of 2 -methoxy isobutyl isonitrile \\
\hline 99mTc-MAA, $148 \mathrm{MBq}(4 \mathrm{mCi})$, assumes 10 doses per kit & $\sim 0.1 \mathrm{mg}$ of aggregated albumin \\
\hline 99mTc-exametazime, $740 \mathrm{MBq}(20 \mathrm{mCi})$, assumes 1 dose per kit & $0.5 \mathrm{mg}$ of exametazine \\
\hline 99mTc-sulfur colloid, $185 \mathrm{MBq}(5 \mathrm{mCi})$, assumes 10 doses per kit & $0.19 \mathrm{mg}$ of sodium thiosulfate and $0.53 \mathrm{mg}$ of gelatin \\
\hline 99mTc-DTPA, $370 \mathrm{MBq}(10 \mathrm{mCi})$, assumes 10 doses per kit & $0.5 \mathrm{mg}$ of pentasodium pentetate \\
\hline 99mTc-disofenin, $185 \mathrm{MBq}(5 \mathrm{mCi})$, assumes 10 doses per kit & $2.0 \mathrm{mg}$ of disofenin \\
\hline 99mTc-DMSA, $185 \mathrm{MBq}(5 \mathrm{mCi})$, assumes 5 doses per kit & $0.24 \mathrm{mg}$ of succimer \\
\hline${ }^{111}$ In-DTPA, 18.5 MBq $(500 \mu \mathrm{Ci})$ & $10-25 \mu \mathrm{g}$ of pentetic acid \\
\hline${ }^{201}$ TI-chloride, $111 \mathrm{MBq}(3 \mathrm{mCi})$ & $16.6 \mathrm{ng}$ of ${ }^{201} \mathrm{TI}$ \\
\hline 123I-Nal, $14.8 \mathrm{MBq}(400 \mu \mathrm{Ci})$ & $0.246 \mathrm{ng}$ \\
\hline 123/-hippuran, 37 MBq (1 mCi) & $2 \mathrm{mg}$ of iodohippurate sodium \\
\hline
\end{tabular}

${ }^{*}$ Compounds added for isotonicity, $\mathrm{pH}$ adjustment, stabilization, reduction, and preservation are not included because they are already judged safe.

Variations are due to variable carrier concentrations, frequency of generator milking, time elapsed since radiopharmaceutical preparation, and number of doses prepared per kit.

\section{PROPOSED SOLUTIONS AND CONCLUSION}

The FDA should contract with the Society of Nuclear Medicine and Molecular Imaging (SNMMI) and the American College of Nuclear Medicine (ACNM) for review of diagnostic radiopharmaceutical investigational-new-drug applications and new-drugapproval applications. The SNMMI and ACNM would appoint a large body of potential reviewers (a radiopharmaceutical advisory committee, or RAC) comprising board-certified nuclear medicine physicians, radiochemists, physicists specializing in nuclear medicine, and nuclear pharmacists, as well as pharmacologists, toxicologists, statisticians, and any other specialists who might be required for review of a particular diagnostic radiopharmaceutical. A chair and vice chair would be chosen, and they would choose a subgroup of review specialists for a particular review. Those specialists would be paid a modest fee for their review work. The review specialists for a particular diagnostic radiopharmaceutical would then determine what safety and efficacy information they need for their review. The RAC would talk to the manufacturers, nuclear pharmacies, or institutions, and when the data were obtained they would review them and make a decision. The FDA would honor that decision, accepting the investigational-new-drug application or approving the new-drug-approval application. The RAC would also determine the indications, which the FDA would honor, and the content of the package insert, which the FDA would also honor. The SNMMI and ACNM would determine the tenure of the chair and vice chair of the RAC. It probably would not be necessary to determine the tenures of various other RAC members, as a subset of the RAC would be chosen anew for each diagnostic radiopharmaceutical review. The SNMMI and ACNM would thereby ensure a highly expert and efficient review process. For example, if someone wanted to put in a new drug application for ${ }^{15} \mathrm{O}$ water (all 5.55 picograms of it), all that would be required would be a presentation of published dosimetry, a detailed description of how it is made and delivered to the patient, its purity, and a request for an indication of blood flow. The applicant would append a bunch of reprints. It is unlikely that anything else would be needed. On the other hand, a new antibody in milligram quantities with a radiolabel would require clinical trials to look at adverse events and efficacy. In this way, radiopharmaceutical-specific requirements for drug approval would fit the drug. This concept of drug-specific requirements is in keeping with present FDA regulations (21 Code of Federal Regulations part 601.30-35).

It will fall to the SNMMI, the ACNM, and the radiopharmaceutical manufacturers to bring about the suggested changes at the FDA. Only then can we again become world leaders in the field, instead of watching other first-world countries approve these radiopharmaceuticals years before us and at a much lower cost.

\section{DISCLOSURE}

No potential conflict of interest relevant to this article was reported.

\section{REFERENCES}

1. United States Pharmacopeia-National Formulary. Rockville, MD: The United States Pharmacopeial Convention; 2008.

2. Siegel JA, Pennington CW, Sacks B. Subjecting radiologic imaging to the linear nothreshold hypothesis: a non sequitur of non-trivial proportion. J Nucl Med. 2017;58:1-6. 